\title{
Pancreatic adenocarcinoma: why and when should it be resected?
}

\author{
D Ravichandran, CD Johnson
}

\begin{abstract}
Summary
Adenocarcinoma of the pancreas is a common and dreadful disease with an extremely poor prognosis. In practice, only a few patients are cured but surgical resection, although feasible in less than $20 \%$ of patients, offers maximum prolongation of life and provides good palliation of symptoms. This can now be performed safely, even in elderly patients, in specialist units. Better radiological imaging and laparoscopy allow selection of resectable tumours effectively. All patients with pancreatic cancer should now be assessed for surgical resection and potentially suitable patients should be referred to a specialist team at an early stage.
\end{abstract}

Keywords: pancreatic neoplasms, adenocarcinoma, pancreatectomy

University Surgical Unit, Southampton General Hospital, Southampton SO16 6YD, UK

D Ravichandran

CD Johnson

Correspondence to $\mathrm{Mr} \mathrm{CD}$ Johnson

Accepted 17 July 1996
Adenocarcinoma of the pancreas is the second commonest gastrointestinal malignancy and the fourth commonest cause of cancer deaths in the western world. It has one of the poorest five-year survival rates (about $3 \%$ ) of all malignancies, ${ }^{1}$ mainly due to advanced disease at presentation. Despite being a common disease, there is no general agreement among clinicians on the indications for and use of different treatment modalities available at present, such as surgical resection and chemotherapy., ${ }^{2,3}$ However, until effective methods of prevention, screening for early disease and more effective therapy for advanced disease are developed, any improvement in the prognosis of this dreadful disease can only be achieved by the efficient use of surgery and chemoradiotherapy. In this article we look at the role of surgical resection in patients diagnosed to have pancreatic adenocarcinoma.

Two-thirds of pancreatic adenocarcinomas occur in the head of the organ and most cases of carcinoma of the body and tail of the pancreas present at an advanced stage which makes surgical resection impossible. Thus the surgical resection discussed here mainly concerns pancreaticoduodenectomy for carcinoma of the head of the pancreas, although most of the arguments are also applicable to left-sided pancreatectomy when the tumour is detected sufficiently early. ${ }^{4}$

\section{Should this patient's tumour be resected?}

This question requires consideration of the merits or otherwise of surgical resection and also of the alternative therapies available and the outcome without resection. The main criticism of surgical resection is that, in the absence of long-term survival, the high morbidity and mortality presumed to be associated with pancreaticoduodenectomy is not justifiable. This view is still prevalent among some surgeons and gastroenterologists who take a nihilistic view in this disease, thus denying the patient the surgical option.

Cure is uncommon in pancreatic cancer and surgical resection, even when deemed 'curative', will only result in an overall five-year survival of $10-20 \%{ }^{5-8}$ and a median survival of about $11-18$ months..$^{5,6,9-12}$ However, resection offers the only chance of cure in this disease, however small that may be, and prolongs the short-term survival. In non-operated patients, even with other palliative measures such as chemo-radiotherapy, two-year survival is uncommon while following surgical resection, $25-40 \%$ of patients will live for two years..$^{5,12-14}$ These improved figures are not simply due to patient selection, as stage for stage, resected patients have been shown to have better survival. ${ }^{15,16}$ In addition to improved short-term survival, many recent studies from specialist units around the world have shown that, in selected groups of patients, such as those with small tumours without lymph node involvement, longer survival is also possible after resection, with five-year survival rates of up to $25 \%$ or more. ${ }^{5,8,11,13,17}$

\section{OPERATIVE MORTALITY}

The first patient on whom Dr Alan Oldfather Whipple carried out a resection of pancreatic tumour followed by reconstruction using catgut sutures in March 1934 died within 48 hours from suture line disruption. ${ }^{18}$ The morbidity and mortality of pancreatic resection remained high up to 1980 . This resulted in some surgeons abandoning surgical resection altogether in favour of palliative measures such as simple bypass ${ }^{19,20}$ and is responsible for the persisting impression that this is a 'dangerous' operation. However, the situation has changed quite dramatically over the last 15 years. Resection can now be performed in most centres with less than $10 \%$ mortality and many studies published in the last 10 years bear witness to this fact (table 1). It is the general consensus that mortality rates over $5 \%$ are excessive. In specialist units the mortality figures are now in the region of $2 \%$ or less and large series of patients 
Table 1 Operative mortality reported for Whipple's pancreaticoduodenectomy for adenocarcinoma of the pancreas since 1980

\begin{tabular}{llll}
\hline Reference & Year & Patients $(n)$ & $\begin{array}{l}\text { Hospital } \\
\text { mortality (\%) }\end{array}$ \\
\hline 53 & $1983-88$ & 25 & 0 \\
13 & $1985-89$ & 46 & 0 \\
10 & $1982-90$ & 53 & 2 \\
8 & $1988-91$ & 53 & 0 \\
52 & $1989-90$ & 128 & 8 \\
6 & $1982-88$ & 555 & 8 \\
\hline
\end{tabular}

undergoing resection without any operative deaths have been reported..$^{8,13}$ In a single institution, the mortality rate has come down from $24 \%$ before 1980 to $2 \%$ at present and morbidity has fallen from $59 \%$ to $36 \% .{ }^{21}$ Undoubtedly, many factors, such as improved anaesthesia, intensive care, parenteral nutrition and prophylactic antibiotics have played a part in this development but the most important reason is thought to be that more pancreatic resections are now performed in specialist units which have a high patient volume and where the resections are done by specialist pancreatic surgeons with shorter operating time and reduced blood transfusion requirements. ${ }^{22}$ There is no place for an occasional pancreatectomist in the management of pancreatic cancer. The difference in the hospital mortality between a high volume regional provider and a smaller unit can be up to sixfold ${ }^{23}$ with the added benefit of reduced intensive care unit stay and total hospital stay resulting in cost savings. At present, in specialist units, the morbidity and mortality of pancreatic resection are not significantly different from that of other major abdominal surgery, such as resection of the rectum. The argument that pancreatic resection carries a high risk of death is thus no longer a valid reason for denying the patient the surgical option.

\section{DIAGNOSTIC ACCURACY}

Tumours in the region of ampulla of Vater, the so-called peri-ampullary tumours, arise from the ampulla, duodenum or the distal common bile duct and are responsible for up to $15 \%$ of carcinomas occurring in the head of the pancreas (box 1). Unlike the ductal adenocarcinoma of the pancreas, the resectability rate is much higher $(80 \%)$ and the five-year survival rate is much better $(30-50 \%)$ after resection. ${ }^{24}$ There is uniform agreement that periampullary tumours should be resected, but unfortunately, these tumours are indistinguishable clinically, radiologically and even intra-operatively from ductal adenocarcinoma of the pancreas. Thus, a uniform policy of not offering resection will mean that some patients with these relatively favourable cancers go unresected.

\section{Could this patient's tumour be resected?}

\section{SHOULD ADVANCED AGE BE A CONTRAINDICATION?}

The number of people aged over 70 years is increasing and pancreatic cancer is mainly a disease of the elderly. The peak incidence is in the eighth decade of life with $70 \%$ of cases in the USA in 1994 occurring in patients over 65 years of age. ${ }^{25}$ Thus, most patients in whom resection is contemplated would be in their 7th or 8th decade. Is resection safe in these elderly patients? Studies have shown that, in general, advanced age is associated with a higher incidence of peri-operative death and is an adverse prognostic factor for operative mortality in pancreatic resection. ${ }^{6,26}$ Due to this risk it is often considered that there is no justification for performing resection in patients over 70 years of age in preference to simple bypass. However, advanced age is often associated with other systemic illnesses ${ }^{27}$ and other studies have demonstrated that when these are considered separately, age alone is not necessarily a risk factor. ${ }^{25,28,29}$ Recent studies of pancreaticoduodenectomy in elderly patients have shown that surgery can be performed with very acceptable $(<5 \%)$ mortality in patients over 70 years of age (table 2 ) and the survival figures are not different from those of younger patients. ${ }^{6,9,25,30}$ Thus, patients should no longer be excluded from surgery on the basis of age alone. The question whether it is justifiable to perform a costly, useful, but non-curative procedure on patients with limited life expectancy in this era of limited health-care resources has moral and ethical implications and a discussion of this subject is beyond the scope of this article. 
Table 2 Morbidity and mortality of pancreatic resection in elderly patients

\begin{tabular}{llllll}
\hline Reference & Year & Age (years) & Patients $(n)$ & Morbidity (\%) & Mortality (\%) \\
\hline 26 & $1940-78$ & $61-70$ & 60 & 35 & 25 \\
57 & $1967-81$ & $>65$ & 17 & 59 & 41 \\
30 & $1968-85$ & $>70$ & 21 & 48 & 10 \\
56 & $1982-87$ & $>70$ & 42 & 31 & 9 \\
54 & $1970-90$ & $>70$ & 42 & 14 & 5 \\
9 & $1970-90$ & $>70$ & 44 & 36 & 4.5 \\
58 & $1974-90$ & $>70$ & 28 & 54 & 18 \\
25 & $1983-94$ & $>70$ & 138 & 45 & 6 \\
8 & $1988-91$ & $>70$ & 37 & 62 & 0 \\
55 & $1987-93$ & $>70$ & 14 & 57 & 0 \\
\hline
\end{tabular}

\begin{tabular}{|ll|}
\hline $\begin{array}{l}\text { American Society of } \\
\text { Anesthesiologists (ASA) } \\
\text { physical status classification } \\
\text { system }\end{array}$ \\
\hline $\begin{array}{l}\text { 31 } \\
\text { I }\end{array}$ & $\begin{array}{l}\text { Patient type } \\
\text { a normal healthy patient } \\
\text { patient with mild systemic } \\
\text { disease } \\
\text { patient with severe systemic } \\
\text { disease that limits activity } \\
\text { but is not incapacitating } \\
\text { patient with an incapacitating } \\
\text { systemic disease that is a } \\
\text { constant threat to life } \\
\text { moribund patient not } \\
\text { III }\end{array}$ \\
IV & with or without surgery \\
V & \\
\end{tabular}

Box 2

\begin{tabular}{|l|}
\hline $\begin{array}{l}\text { Resection for pancreatic } \\
\text { adenocarcinoma }\end{array}$ \\
\hline - only $10-20 \%$ of patients are suitable \\
- morbidity and mortality have fallen \\
in recent years in specialist units \\
- not usually curative but provides the \\
maximum prolongation of life and \\
best palliation \\
- contrast enhanced CT is presently \\
the best method of assessment for \\
resectability \\
\hline
\end{tabular}

Box 3

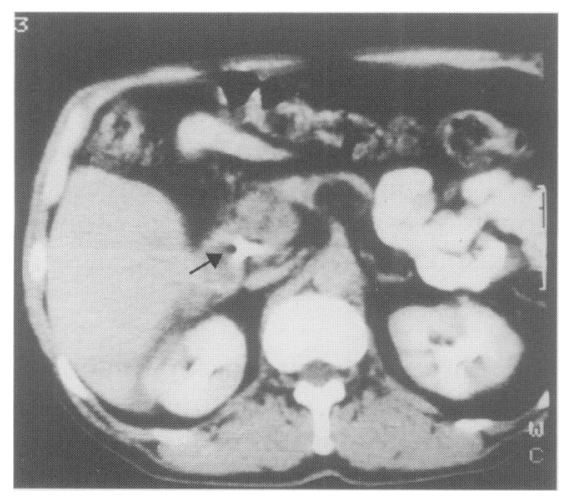

Figure Streak artefacts on the CT due to a previously inserted biliary stent (arrow)

\section{CO-MORBID CONDITIONS}

Other systemic illnesses such as diabetes mellitus, essential hypertension, atherosclerotic and cardiovascular disease, chronic pulmonary disease and renal disease are often present in patients with pancreatic cancer. These increase the risk of surgery and leave little margin for error. Routine pre-operative assessment as for other major abdominal surgery is usually sufficient but in the presence of any of the above illnesses special consideration of the case is needed, with joint assessment by the surgeon and the anaesthetist. The American Society of Anesthesiologists (ASA) classification system ${ }^{31}$ (box 2) is commonly used in the pre-operative assessment and most patients who belong to ASA classes I or II can safely undergo pancreatic resection while endoscopic or percutaneous methods of palliation are more appropriate for ASA class IV patients. Patients in class III require individual decision making, based on current symptoms, age and the extent of the primary tumour.

\section{IS THIS TUMOUR SUITABLE FOR RESECTION?}

The next step, when a pancreatic carcinoma is diagnosed in a patient fit to withstand resection, is the assessment of resectability. Unfortunately most patients with pancreatic cancer present with metastatic or locally advanced disease. Local extension of the disease may involve the adjacent organs and major blood vessels while metastatic deposits are found commonly in the liver and the lymph nodes. Surgical resection for potential cure can only be performed if the disease is confined to the pancreas and this is the case in only $10-20 \%$ of patients. Carcinoma of the body and tail of pancreas usually presents too late for curative resection and resection rates may be half those of pancreas head tumours. ${ }^{4}$

Clinical assessment of resectability is usually not accurate due to the retroperitoneal location of the pancreas unless there are obvious signs of advanced malignancy such as malignant ascites or supraclavicular lymphadenopathy. Pre-operative assessment of resectability can be performed with reasonable accuracy using ultrasonography, computed tomography (CT), CT with superior mesenteric arterial portography, angiography or magnetic resonance imaging (MRI). These investigations may avoid an unnecessary laparotomy in patients who are unlikely to be helped by surgical intervention. CT should be carried out whenever possible before the insertion of a biliary stent for jaundice to avoid streak artefacts during the CT examination (figure). The radiological criteria of unresectability are listed in box 4 . It should be noted, however, that these are not absolute as some surgeons perform pancreatic resections even when there is evidence of vascular invasion, with resection and reconstruction of major vessels, although it is questionable whether it prolongs survival..$^{32}$

\section{Ultrasound}

Ultrasound is often the first investigation done in patients with obstructive jaundice, upper abdominal pain or a mass. Simple and noninvasive, it may reveal the presence of liver deposits or ascites associated with a hypo-echoic pancreatic mass, which will serve to avoid any further investigations except histological or cytological confirmation. However, the examination is technically inadequate in 15-20\% of patients, often due to overlying bowel gas and obesity. In addition local assessment of resectability is often unsatisfactory.

\section{Endoscopic ultrasound}

Endoscopic ultrasound can give high resolution images of the pancreas, bile duct and surrounding organs and blood vessels. It has been reported to be the most accurate method available for the tumour and lymph node staging, especially with small tumours. ${ }^{33,34}$ The method is not yet widely available for 


\begin{tabular}{|l|}
\hline Features suggesting \\
unresectability in pre- \\
operative investigations \\
\hline Distant disease \\
- hepatic, lung or rarely other \\
metastases \\
- peritoneal or omental metastases \\
including malignant ascites \\
- lymph node deposits which would \\
not be included in the resected \\
surgical specimen \\
Extrapancreatic extension of disease \\
- for example, into the \\
hepatoduodenal ligament, \\
duodenum, mesocolon or \\
mesenteric root \\
Major vascular involvement \\
- portal vein or superior mesenteric \\
vessels \\
\hline
\end{tabular}

Box 4 clinical use and, due to the limited penetration of high frequency ultrasound, distant disease such as liver deposits may not be detected with this method.

\section{$C T$}

CT is the most useful investigation in the assessment of resectability at present. It demonstrates the extent of local tumour extension, peripancreatic nodal involvement and involvement of major vessels. For best results a high quality spiral scanner capable of producing high resolution scans and thin sections should be used. Oral contrast is given to opacify the upper gastrointestinal tract and scans are done during the arterial and delayed phases of an intravenous dose of contrast. CT is more accurate in predicting unresectability than resectability and up to one third of tumours considered resectable by CT may be found to be irresectable at operation..$^{35,36}$ This is due to some limitations of CT such as failure to diagnose vascular invasion in some cases and small $(<2 \mathrm{~cm})$ liver metastases. These limitations may be less with the new generation of spiral scanners.

\section{Superior mesenteric arterial portography}

Combining CT with superior mesenteric arterial infusion of iodinated contrast medium (CTAP) results in clear outlining of superior mesenteric artery, superior mesenteric vein and portal vein. Displacement of vessels by tumour, vascular encasement (tumour cuff), narrowing or irregularity of vessels due to tumour, thrombosis or occlusion all suggest vascular involvement. CTAP has equal or better efficacy in identifying vascular involvement compared with angiography ${ }^{37,38}$ and unlike angiography the relationship between the tumour and vessels can be visualised. It is also the most accurate investigation for detection of liver metastases. ${ }^{39,40}$ However, its value is diminished in the presence of biliary obstruction because the negative contrast of dilated intrahepatic bile ducts is indistinguishable from a non-enhancing metastasis.

\section{Angiography}

Angiography of the coeliac axis arteries and the superior mesenteric artery is a specific but not very sensitive method of assessing tumour involvement of major vessels around the pancreas. It does not provide significantly more information than a good CT scan ${ }^{36}$ which is not invasive. CTAP provides more complete imaging $^{37}$ and angiography alone is not the standard preoperative staging investigation in most centres. One valuable feature of angiography (which must be done as part of CTAP) is the demonstration of aberrant vascular anatomy in the area of the pancreas which may be present in up to one-third of cases. It may also prove useful when CT or MRI findings are equivocal but is likely to be superseded for staging and vascular mapping by spiral CT.

\section{$M R I$}

MRI is an evolving imaging modality in pancreatic cancer. Recent advances such as fat suppression, respiratory motion artefact compensation techniques, the use of glucagon to suppress bowel peristalsis artefacts, and the use of oral and intravenous contrast have contributed to improved accuracy in the staging of pancreatic cancer. ${ }^{41}$ Like CT, it can also demonstrate local tumour extension, liver metastases and vascular involvement but it does not seem to have much advantage over CT at present. ${ }^{42}$ It may be useful when an optimal CT cannot be obtained, such as in cases of streak artefacts from surgical clips or where a biliary stent is in place.

\section{Laparoscopy}

Small $(1-2 \mathrm{~mm})$ peritoneal and omental metastases, common in pancreatic carcinoma, cannot be detected by any radiological methods described above, but would contraindicate resection. Thus, in patients deemed resectable by preoperative investigations, these small metastases should be excluded by laparoscopy before the surgical incision is made. This may also reveal unsuspected liver metastases and evidence of portal hypertension suggesting vascular involvement. Laparoscopy will allow biopsy of the tumour, peritoneal cytology or even fine-needle aspiration of a suspicious lymph node.

\section{Laparoscopic ultrasound}

By introducing an ultrasonographic transducer through the laparoscopic cannula the extent of local tumour invasion and lymph node enlargement can be identified, as well as small liver metastases. ${ }^{43}$ This combination of techniques promises much in the way of visual inspection, targeted biopsy, high resolution ultrasound of liver and pancreas and detection of peritoneal deposits. Preliminary reports are encouraging and further studies are awaited with interest. 
IS BIOPSY CONFIRMATION NECESSARY BEFORE RESECTION?

A mass in the head of the pancreas can also be caused by benign conditions such as chronic pancreatitis. However, a negative biopsy does not eliminate the possibility of malignancy. In a symptomatic patient in whom radiology reveals a clearly resectable tumour in the head of the pancreas, no pre-operative biopsy confirmation is necessary ${ }^{22,44}$ as the mass will be resected regardless of the aetiology and histological confirmation, if necessary, can be obtained during surgery. This will eliminate the small risk of tumour spillage into the peritoneum in these potentially curable patients. A biopsy may be indicated only if the tumour is deemed inoperable, especially if chemo- or radiotherapy is considered.

\section{SELECTION FOR OPERATION}

In conclusion, the aim of pre-operative staging is to choose the small group of patients who have tumours that are resectable for potential cure in a costeffective manner and to avoid subjecting other patients to an unnecessary laparotomy. When there is no evidence of disseminated disease in transabdominal ultrasound, a contrast-enhanced dynamic CT is the next investigation of choice. If the CT suggests that the tumour is unresectable no further investigations are necessary as the accuracy of CT in predicting unresectability is nearly $100 \%$. However, if the CT suggests a resectable tumour, CTAP and/or laparoscopy should be performed as the accuracy of CT in predicting resectability may be as low as $70 \%$. Angiography and MRI is only necessary if a good quality CT cannot be obtained. Angiography is part of the CTAP and provides a pre-operative 'road map' of arterial anatomy in the peripancreatic region.

Finally, it should be emphasised that none of the investigations available at present can predict resectability with $100 \%$ accuracy. The final assessment of resectability of a pancreatic adenocarcinoma can only be made during laparotomy by trial dissection. The rapid advances occurring in imaging technology should cut down the number of unfortunate patients who are deemed unresectable after reaching this stage.

\section{Should resection be offered as a palliative measure?}

Only about $15 \%$ of patients with pancreatic cancer are resectable for potential cure at presentation and most such resections eventually prove to be palliative as patients usually die of recurrent disease, even those who survive more than five years. However, whether resection should be offered frankly as a palliative measure is controversial. A palliative resection can be defined as one in which the surgeon leaves visible tumour behind or one where subsequent histological examination of the resected specimen reveals the presence of tumour at the resection margin. Sometimes there is no choice but to do a palliative resection. For example, during surgery of a tumour deemed resectable by pre-operative investigations, once most of the dissection and transection of pancreas is completed, the surgeon may find that the tumour invades the portal vein posteriorly. Some surgeons would resect and reconstruct the portal vein in this situation. However, once portal vein is involved, resection is not associated with improved survival ${ }^{5,32}$ so most others, who consider portal vein invasion as a sign of advanced disease, would leave behind a cuff of tumour attached to the vein. Many studies have shown that, whenever microscopic tumour is left behind, there is no or very modest survival advantage with resection, the median survival is usually in the region of 10 months..$^{5,11}$ Thus, palliation of symptoms with maximisation of the quality of remaining life becomes the primary outcome measure. In this respect, resection would appear to perform at least as well as other currently available methods of palliation such as surgical bypass and endoscopic palliation with some added advantages. Prospective randomised studies which compare resection with other forms of palliation are lacking. Patients with advanced disease (ASA class IV) or who are unfit for surgery (classes III or IV) are better palliated by endoscopic and percutaneous methods than by surgery.

The question of palliative resection is worth considering now due to the safety of this operation in specialist units. The quality of life of pancreatic cancer patients is mainly impaired by obstructive jaundice, duodenal obstruction, pain and by cancer cachexia. Gastrojejunostomy and choledochojejunostomy following resection, like surgical bypass, offer long-term solutions to the first two problems. The pain may be due both to invasion of retroperitoneal nerves and obstruction of the pancreatic duct. Resection of tumour decompresses the pancreatic duct system and intra-operative coeliac axis block relieves pain effectively. McLeod et $a l^{45}$ found that, once initial convalescence is over, the 
quality of life of resected patients was similar to that of those who had had a simple cholecystectomy. This is in sharp contrast to the common perception that survivors are usually debilitated by severe gastrointestinal symptoms and pancreatic endocrine and exocrine deficiency. In another study, using hospitalfree survival as the main quality-of-life measure, resection was shown to provide the best palliation in class III patients. ${ }^{46}$ Others have found that quality of life was better following resection compared with simple surgical bypass. ${ }^{47}$ Pyloruspreserving pancreaticoduodenectomy may be more suitable as the palliative measure than standard Whipple's resection as the incidence of subsequent nutritional problems is less, ${ }^{48}$ and more patients seem to return to the premorbid state after the former procedure. ${ }^{49}$ Furthermore, the only reliable way of arresting or reversing the process of cancer-related cachexia is removal of the tumour. Thus, resection may have a beneficial, albeit temporary, effect on the cachexia which accompanies pancreatic cancer. There is also an ill-defined psychological benefit to the patient, in the knowledge that most of the cancer is removed. This may contribute to a more positive outlook towards life and may make the patient more receptive towards other treatment modalities offered.

In conclusion, the question whether surgical resection should be offered as a palliative procedure is worth consideration in specialist units where the operation can be performed with acceptable mortality and morbidity. The time has come for a prospective randomised study comparing the effect of palliative resection with other palliative measures on the quality of life of patients with pancreatic cancer.

\section{Adjuvant therapy}

Adjuvant chemo- and/or radiotherapy is one way to improve the local control of the disease and the length of survival of patients who undergo surgery. As the survival after resection is poor it could be argued that some attempt to improve on this is essential. Some studies of adjuvant therapy have reported promising results with improved short-term survival. Bakkevold et a $t^{50}$ reported $43 \%$ twoyear survival and a median survival of 23 months in patients treated with adjuvant chemotherapy while the Gastrointestinal Tumour Study Group ${ }^{51}$ has reported $46 \%$ two-year survival with combined chemo-radiotherapy. Resection, by reducing the tumour burden, may make subsequent chemo-radiotherapy more effective.

\section{Conclusions}

Surgical resection, although only feasible in a small proportion of patients with pancreatic cancer, provides the only chance of cure, the best palliation and maximum prolongation of life in this disease. It also allows maximum benefit from chemo-radiotherapy. Resection can now be performed safely in specialist units. Thus, every patient with pancreatic cancer, except those who are very ill or with disseminated disease at presentation, should be assessed by a specialist pancreatic surgeon. Physiological state rather than chronological age should be considered when assessing fitness for surgery and most patients who belong to ASA classes I-III would be suitable. Dynamic contrast-enhanced CT is at present the best pre-operative method of assessing local invasion. Palliative resection, although it does not prolong survival, gives good quality of life and may be considered in specialist units as an alternative to surgical bypass and endoscopic stenting in low-risk patients.

1 National Cancer Institute. Annual Cancer Statistics Review 1973-1988. Bethesda, Md: Department of Health and Human Services, 1991 (NIH publication no 91-2789)

2 Glazer G, Coulter C, Crofton ME, et al. Controversial issues in the management of pancreatic cancer: Part One A debate held at pancreatic cancer: Part One. A debate held at St Mary's Hospital, London on 18 November 1993. Ann R Coll Surg Engl 1995; 77: 111-22. Glazer G, Coulter C, Crofton ME, et al. Controversial issues in the management of pancreatic cancer: Part Two. A debate held at St Mary's Hospital, London on 18 Novembe 1993. Ann R Coll Surg Engl 1995; 77: 174-80.

4 Johnson CD, Schwall G, Flechtenmacher J, Trede M. Resection for adenocarcinoma of the body and tail of the pancreas. BrF Surg 1993; 80: $1177-9$

5 Yeo CJ, Cameron JL, Lillemoe $\mathrm{KD}$, et al. Pancreaticoduodenectomy for cancer of the head of the pancreas. 201 patients. Ann Surg 1995; 221: $721-33$.
6 Baumel H, Huguier M, Manderscheid JC, Fabre JM, Houry S, Fagot H. Results of resection for cancer of the exocrine pancreas: a study from the French association of surgery. Br $¥$ Surg 1994; 81: $102-7$.

7 Bodner E. Leistungen der tumorchirurgie bei tumoren de bauchspeicheldruse. Langenbecks tumoren de bauchspeicheldruse.

8 Arch Chir 1988; suppl 2: $133-8$.

Cameron JL, Pitt HA, Yeo CJ, et al. One hundred and forty-five consecutive pancreatico-
duodenectomies without mortality. Ann Surg duodenectomies with

9 Hannoun L, Christope M, Ribeiro J, et al. A report of forty-four instances of pancreaticoduodenal resection in patients more than seventy years of age. Surg Gynaecol Obstet 1993; 177: 556-60.

10 Roder JD, Stein HJ, Huttl W, Siewert JR. Pylorus-preserving versus standard pancraticoduodenectomy: An analysis of 110 pancreatic and periampullary carcinomas. Br $\mathcal{f}$ Surg 1992; 79: $152-5$.
11 Nitecki SS, Sarr MG, Colby TV, Van Heerden JA. Long-term survival after resection for ductal adenocarcinoma of the pancreas. Is it really improving? Ann Surg 1995; 221: 59-66.

12 Geer RJ, Brennan MF. Prognostic indicators for survival after resection of pancreatic adenocarcinoma. Am ₹ Surg? 1993; 165: 68-73.

13 Trede M, Schwall G, Seager HD. Survival after pancreatoduodenectomy. 118 consecutive resections without an operative mortality. Ann Surg 1990; 211: $447-58$.

14 Klinkenbijl JHG, Jeekel J, Schmitz PIM, et al. Carcinoma of the pancreas and periampullary region: palliation versus cure. Br F Surg 1993; 80: $1575-8$.

15 Matsuno S, Sato T. Surgical treatment for carcinoma of the pancreas. Experience in 272 patients. Am f Surg 1986; 152: 499-504.

16 Chandiramini VA, Theis BA, Russell RCG. Role of resection in the management of pancreatic cancers. Gut 1990; 31: A488. 
17 Tsuchiya R, Noda T, Harada N, et al. Collective review of small carcinomas of the pancreas. Ann Surg 1986; 203: $77-81$.

18 Peters JH, Carey LC. Historical review of pancreaticoduodecnectomy. Am f Surg 1991; 161: $219-25$.

19 Crile G, Jr. The advantages of bypass operations over radical pancreatoduodenectomy in the over radical pancreatoduodenectomy in the treatment of pancreatic carcino
Obstet 1970; 130: 1049-53.

20 Shapiro TM. Adenocarcinoma of pancreas. A statistical analysis of biliary bypass vs Whipple resection in good risk patients. Ann Surg 1975; 182: $715-21$.

21 Crist DW, Sitzmann JV, Cameron JL. Improved hospital morbidity, mortality and survival after the Whipple procedure. Ann Surg 1987; 206: $358-65$.

22 Lillemoe $\mathrm{KD}$. Current management of pancreatic carcinoma. Ann Surg 1995; 221: $133-48$

23 Gordon TA, Burleyson GP, Tielsch JM, Cameron JL. The effects of regionalization on cost and outcome for one general high risk surgical procedure. Ann Surg 1995; 221: 43-49.

24 Ihse I, Andersson R, Axelson J, Kobari M, Andren-Sandberg A. Periampullary tumours. In:
Neoptolemos JP, Lemoine NR, eds. Pancreatic Neoptolemos JP, Lemoine NR, eds. Pancreatic
cancer. Molecular and clinical advances. Oxford: cancer. Molecular and clinical advances.

25 Fong Y, Blumgart LH, Fortner JG, Brennan MF. Pancreatic or liver resection for malignancy is safe and effective for the elderly. Ann Surg 1995; 222: 426- 37.

26 Herter FP, Cooperman AM, Ahlborn TN, Antinori C. Surgical experience with pancreatic and periampullary cancer. Ann Surg 1982; 195: $274-81$.

27 Hosking MP, Warner MA, Lobdell CM, Offord $\mathrm{KP}$, Melton LJ. Outcomes of surgery in patients
90 years of age and older. $\mathcal{f} A M A 1989 ; 261$ : 90 years
$1909-15$.

28 Gilsdorf RB, Spanos P. Factors influencing morbidity and mortality in pancreaticoduodenectomy. Ann Surg 1973; 177: 332-7.

29 Zenilman ME. Surgery in the nursing home patient. Surg Clin North Am 1994; 74: 63-77.

30 Kairaluoma MI, Kiviniemi H, Stahlberg M. Pancreatic resection for carcinoma of the pancreas and the periampullary region in patients over 70 years of age. Br 7 Surg 1987: 74: $116-8$.

31 Owens WD, Felts JA, Spitznagel EL. ASA physical status classifications: A study of conpistency ratings. Anaesthesiology 1978; 49: 239 43.

32 Allema JH, Reinders ME, van Gulik TM, et al. Portal vein resection in patients undergoing pancreatoduodenectomy for carcinoma of the pancreatic head. Br $\mathcal{F}$ Surg 1994; 81: $1642-46$.
33 Hawes RH, Zaidi S. Endoscopic ultrasonography of the pancreas. Gastrointest Endosc Clin North Am 1995; 5: $61-80$.

34 Muller MF, Meyenberger C, Bertschinger P, Schaer R, Marincek B. Pancreatic tumours: Evaluation with endoscopic US, CT, and MR imaging. Radiology 1994; 190: 745-51.

35 Moosa AR, Gamagami RA. Diagnosis and staging of pancreatic neoplasms. Surg Clin North staging of pancreatic ne.

36 Nghiem HV, Freeny PC. Radiologic staging of pancreatic adenocarcinoma. Radiol Clin North Am 1994; 32: 71 - 79 .

37 Savader BL, Fishman EK, Savader SJ, Cameron JL. CT arterial portography vs pancreatic arteriography in the assessment of vascular involve ment in pancreatic and periampullary tumours. 7 Comp Assist Tomogr 1994; 18: 916-20.

38 Soyer P, Lacheheb D, Belkacem A, Levesque M. Involvement of superior mesenteric vessels and portal vein in pancreatic adenocarcinoma. Detection with CT during arterial portography. Abdom Imaging 1994; 19: 413-6.

39 Matsui O, Takashima T, Kadoya M, et al. Liver metastases from colorectal cancers: Detection with CT during arterial portography. Radiology with CT during ar

40 Heiken JP, Weyman PJ, Lee JKT, et al. Detection of focal hepatic masses. Prospective evaluation with CT, delayed CT, CT during arterial portography, and MR imaging. Radiology 1989 171: $47-51$.

41 Mitchell DG. MR imaging of the pancreas. MRI Clin North Am 1995; 3: 51 - 71 .

42 Megibow AJ, Zhou XH, Rotterdam $\mathrm{H}$, et al. Pancreatic adenocarcinoma: CT versus MR imaging in the evaluation of resectability. Report of the radiology diagnostic oncology group. Radiology 1995; 195: $327-32$.

43 John TG, Greig JD, Carter DC, Garden OJ. Carcinoma of the pancreatic head and periamCarcinoma of the pancreatic head and periam-
pullary region. Tumour staging with laparoscopy pullary region. Tumour staging with laparoscopy
and laparoscopic ultrsonography. Ann Surg and laparoscopic ul

44 Warshaw AL, Castillo CF. Pancreatic carcinoma. N Engl f Med 1992; 326: 455-65.

45 McLeod RS, Taylor BR, O'Connor BI, et al. Quality of life, nutritional status and gastrointestinal hormone profile following the Whipple procedure. Am F Surg 1995; 169: 179-185.

46 Yasue M, Sakamoto J, Morimoto $\mathrm{T}$, et al. Evaluation of the effect of pancreatic resection in advanced pancreatic cancer with special reference using hospital-free survival as a measure of quality of life. Ipn f Clin Oncol 1995; 25: $37-45$.
47 Bakkevold KE, Kambestad B. Palliation of pancreatic cancer. A prospective multicentre study. Eur f Surg Oncol 1995; 21: 176-82.

48 Kozuschek W, Reith HB, Waleczek H, Haarmann W, Edelmann M, Sonntag D. A comparison of long term results of the standard Whipple procedure and the pylorus preserving pancreatoduodenectomy. F Am Coll Surg 1994; 178: 443-58.

49 Yasuda $H$, Takada $T$, Uchiyama K, Hasegawa $\mathrm{H}$. Social function following pylorus-preserving pancreaticoduodenectomy for cancer of the head of the pancreas. Asian f Surg 1993; 16: 228-31

50 Bakkevold KE, Arnesjo B, Dahl O, Kambestad B. Adjuvant combination chemotherapy (AMF) following radical resection of carcinoma of the pancreas and papilla of Vater - Results of a controlled prospective randomised multicentre study. Eur $\mathcal{f}$ Cancer 1993; 29A: 698-703.

51 Gastrointestinal Tumor Study Group. Further evidence of effective adjuvant combined radiation and chemotherapy following curative resection of pancreatic cancer. Cancer 1987; 59: $2006-10$.

52 Edge SB, Schmieg RE, Rosenlof LK, Wilhelm MC. Pancreas cancer resection outcome in American university centres in 1989-1990. Cancer 1993; 71: 3502-8.

53 Lygidakis NJ, van der Heyde MN, Allema JH, Tytgat GNJ, Houthoff HJ, van Leeuwen D Subtotal duodenopancreatectomy for pancreatic duct, distal bile duct and periampullary carcinoma: short and long term results. Am 7 Gastroenterol 1989; 84: $917-20$.

54 Delcore R, Thomas JH, Hermreck AS. Pancreaticoduodenectomy for malignant pancreatic and periampullary neoplasms in elderly patients. $\mathrm{Am}$ periampulary neoplasms in

55 Karl RC, Smith SK, Fabri PJ. Validity of major cancer operations in elderly patients. Ann Surg Oncol 1995; 2: $107-113$

56 Spencer MP, Sarr MG, Nagorney DM. Radical pancreatectomy for pancreatic cancer in the elderly. Is it safe and justified? Ann Surg 1990; 212: $140-3$.

57 Lerut JP, Gianello PR, Otte JB, Kestens PJ. Pancreaticoduodenal resection. Surgical experience and evaluation of risk factors in 103 patients. Ann Surg 1984; 199: 432-7.

58 Kayahara $M$, Nagakawa $T$, Ueno $K$, Ohta $T$, Takeda T, Miyazaki I. Pancreatic resection for periampullary carcinoma in the elderly. $\mathcal{F}_{p} \mathcal{F}^{\prime}$ Surg 1994; 24: 229-33. 